\title{
Manifestaciones cutáneas secundarias a la pandemia de COVID-19
}

\section{Cutaneous manifestations secondary to the COVID-19 pandemic}

\author{
Beatriz García de Acevedo Chávez, * Gilberto Adame Miranda, * Rocío Aguilar Mosqueda, * \\ María Isabel Arias Gómez, ${ }^{*}$ Josefina Carbajosa Martínez, ${ }^{*}$ Adriana Miranda Gómez, * Heidi Muñoz Hink* \\ Citar como: García de Acevedo CB, Adame MG, Aguilar MR, Arias GMI, Carbajosa MJ, Miranda GA et al. Manifestaciones cutáneas \\ secundarias a la pandemia de COVID-19. Acta Med Grupo Angeles. 2021; 19 (s1): s27-s36. https://dx.doi.org/10.35366/101025
}

\section{Resumen}

En la literatura médica se han descrito las reacciones en piel asociadas al síndrome respiratorio agudo severo. Pocas son las publicaciones acerca de las dermatosis que indirectamente están relacionadas con la pandemia y que han aumentado su incidencia. El presente trabajo es una revisión de las farmacodermias al tratamiento de la COVID-19, de las lesiones en la piel por el uso de equipos de protección personal y un grupo de enfermedades de este órgano que han aumentado su incidencia, como acné, rosácea, dermatitis seborreica y herpes zóster.

Palabras clave: COVID-19, equipo de protección personal, dermatitis de contacto, maskné.

\section{INTRODUCCIÓN}

A finales del año 2019 se descubrió el virus del síndrome respiratorio agudo severo (SARS-CoV-2), que resultó en una nueva enfermedad Ilamada COVID-19. Inició en Wuhan, y rápidamente se esparció por China y a todo el mundo.

Se han descrito manifestaciones cutáneas primarias relacionadas con esta enfermedad y se pueden clasificar en cinco patrones clínicos: maculopápulas 47\%, lesiones de urticaria $19 \%$, seudosabañones $19 \%$, erupciones vesiculares $9 \%$ y livedo o necrosis $6 \% .{ }^{1}$ Un grupo de dermatosis, que no son causadas directamente por el virus, han aumentado significativamente durante la pandemia y se consideran manifestaciones cutáneas secundarias relacionadas con la COVID-19. El espectro va desde farmacodermias a

\section{Abstract}

In the medical literature, the skin reactions related to the acute respiratory distress syndrome have been fully described. There are few reports of the skin diseases indirectly related to the pandemic, which have increased in incidence. This review focuses on skin problems related with COVID-19, including adverse drug reaction to its treatments, personal protective equipment skin reactions and secondary cutaneous involvements due to circumstances during the pandemic, including acne, rosacea, seborrheic dermatitis and herpes zoster.

Keywords: COVID-19, personal protective equipment, contact dermatitis, maskne.

los medicamentos empleados en un intento de tratar la enfermedad, dermatosis por el equipo de protección que emplean los que se encuentran en la primera línea del combate de la enfermedad, al igual que el resto de la población mundial con los cubrebocas y el uso de geles antibacteriales, y finalmente otras dermatosis, como el acné, rosácea, dermatitis seborreica y herpes zóster, cuya incidencia también se ha visto incrementada.

\section{FARMACODERMIAS}

Los pacientes con COVID-19 tienen un mayor riesgo de presentar reacciones adversas a fármacos, o interacciones entre los mismos, que causan reacciones cutáneas similares a las descritas como asociadas al SARS-CoV-2. ${ }^{2}$
* Dermatólogo de práctica privada. Ciudad de México.

www.medigraphic.com/actamedica
Correspondencia:

Beatriz García de Acevedo Chávez

Correo electrónico: beatriz_garciadea@hotmail.com

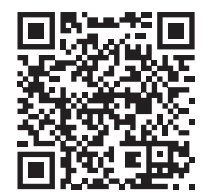


En el estudio de Esther E. Freeman y colegas, con 716 pacientes de 31 países, el 55\% recibió antipalúdicos y el $50 \%$ antibióticos (azitromicina 56\%, ceftriaxona 37\%, vancomicina $37 \%$, piperacilina-tazobactam $29 \%$ y doxiciclina $27 \%){ }^{3}$ Las reacciones en piel más frecuentes con este tipo de medicamentos se describen en la Tabla $1 .{ }^{4}$

\section{Farmacodermias por terapias alternativas}

Las circunstancias actuales de buscar terapias alternativas para evitar la replicación, propagación o infección por SARS-CoV-2 han hecho que se abuse de moléculas como zinc, vitaminas C, D y ácido fólico o cúrcuma, presentando una mayor incidencia de farmacodermias, por ejemplo eritema pigmentado fijo o eritema anular centrifugo, al exceder la dosis óptima de ingesta diaria. Las lesiones en piel asociadas con estas sustancias se describen en la Tabla 2.5

\section{MANIFESTACIONES CUTÁNEAS POR EL USO DE EQUIPO DE PROTECCIÓN PERSONAL (EPP)}

Los trabajadores de la salud en la primera línea de batalla en contra de la COVID-19, para mantenerse aislados del

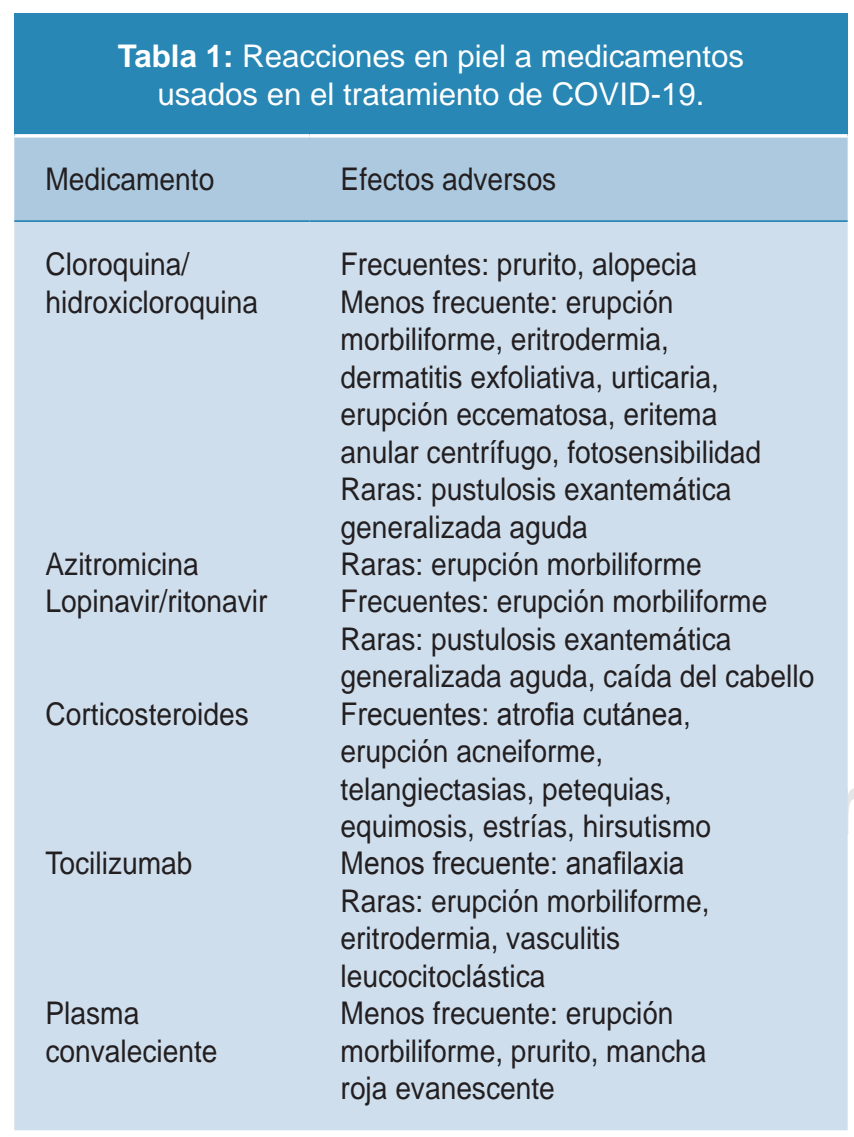

\begin{tabular}{|c|c|}
\hline \multicolumn{2}{|c|}{$\begin{array}{l}\text { Tabla 2: Dermatosis asociadas al } \\
\text { uso de terapias alternativas. }\end{array}$} \\
\hline Molécula & Reacción en piel \\
\hline Vitamina C & Angioedema, eccema, eritema, rubor \\
\hline Vitamina D & Granuloma perforante, prurito \\
\hline Vitamina $\mathrm{E}$ & $\begin{array}{l}\text { Dermatitis de contacto, eritema } \\
\text { multiforme, exantemas }\end{array}$ \\
\hline Jengibre & Dermatitis \\
\hline Cúrcuma & Dermatitis de contacto \\
\hline
\end{tabular}

virus, empezaron a usar EPP. El tipo de EPP depende de la profesión; es diferente el que se necesita como militar o policía, para el químico que está en contacto con el material biológico, el del personal médico, al de la población general.

El EPP para la plantilla médica incluye: lentes protectores (goggles), máscaras, cubrebocas KN-95, overoles ahulados, guantes de látex o nitrilo en varias capas y botas de hule para poder aislarlos del acercamiento directo con el germen, cubriendo así ojos, nariz, boca, cuello, manos y cuerpo completo (Figura 1). En cambio, la población general suele utilizar máscaras, caretas y guantes de látex y nitrilo. ${ }^{6}$

Uno de los factores de riesgo más importantes para el desarrollo de manifestaciones cutáneas secundarias al EPP es su uso prolongado, en ocasiones por más de 6-8 horas en promedio. Por lo que las complicaciones que se presentan son relacionadas al sellado, la fricción, la presión y el calor que se genera y se mantiene adentro. El 56.7\% usó el EPP por más de 6 horas y el $64.5 \%$ se encontraban empapados al retirarlo, lo que sugiere que la eficacia de la seguridad se va perdiendo con el aumento de la sudoración.

El EPP está hecho de diversos materiales que pueden causar daño directo a la piel por sí mismos, con dermatitis de contacto. Esta enfermedad empeora porque el tiempo de uso prolongado aumenta la humedad y macera esta superficie, que lleva a la pérdida de la barrera cutánea y favorece la sobreinfección. ${ }^{7,8}$

\section{Lavado de manos, geles antibacteriales y desinfectantes}

Desde el inicio de la pandemia, "lavarse las manos con suficiente agua y jabón por lo menos por 20-30 segundos" se ha convertido en un mantra omnipresente. Durante esta plaga, en un estudio se observó un aumento en la frecuencia de este lavado, de cinco a 10 veces al día, a 10 a 20 veces, sin una diferencia significativa entre trabajadores médicos COVID o no COVID. ${ }^{9}$ Este lavado, aunado 


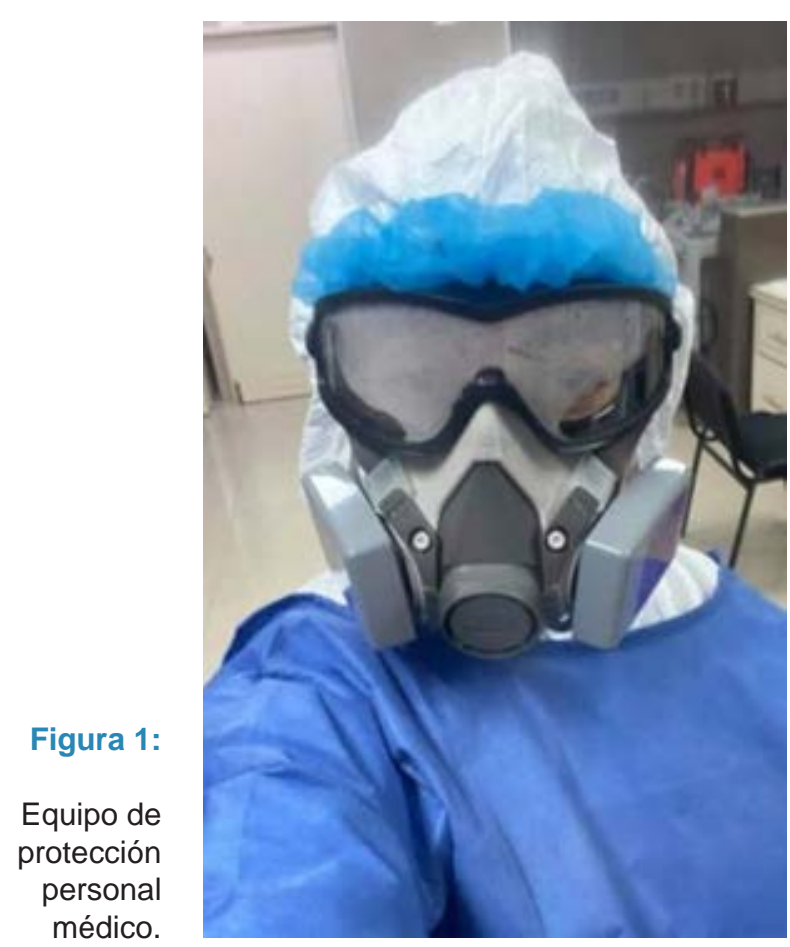

al alcohol al 70\% en gel y el uso prolongado de guantes, conlleva a una alteración en la flora y la barrera natural de protección de la piel y finalmente a un aumento de las dermatitis de contacto por irritantes y sustancias alergénicas (Figura 2). Esta afección de roce se ha presentado durante la pandemia en $74.5 \%$, en comparación con aquella ocupacional registrada, previa a la calamidad, de 31\%.

En una encuesta en 330 trabajadores chinos, reportaron daño cutáneo en el 71\%, con síntomas como picazón, ardor, escozor, signos de resequedad con escamas, además de pápulas, eritema y maceración. El $66 \%$ tuvo un incremento en el lavado de manos de más de 10 veces en 24 horas. ${ }^{7}$

Un estudio de Seemal y colaboradores reportó un incremento de las dermatitis de contacto entre 10-15\%, tanto alérgicas como irritativas. Los síntomas en los casos agudos fueron prurito, vesículas, eritema y escama, y los crónicos con liquenificación e hiperpigmentación. ${ }^{10}$ En un estudio en Gales, Reino Unido, encuestaron a 72 trabajadores de un hospital del área COVID y fuera de ésta. La variante de contacto irritativa de manos fue de $62.5 \%$, que en $14 \%$ empeoraba con el estrés emocional. ${ }^{11}$

Los desinfectantes más frecuentes contienen $75 \%$ de etanol e iodoformo, pero también tienen mezclas con clorhexidina, triclosán, fragancias y lauril sulfato de sodio, los cuales podrían actuar siendo alérgenos o irritantes. En cuanto a la desinfección con alcohol antes de la pandemia se aplicaban de 10 a 20 veces por día, aumentando después hasta 20 a 30 veces por día. Se han reportado eccemas de manos en $93.2 \%$ en el grupo de médicos que no atendían COVID y $85 \%$ entre los que sí la atendían. ${ }^{9}$ También aumentó la aplicación de crema en esa piel, de una vez al día, a dos veces al día.

\section{Guantes}

Los guantes pueden ser de látex y contener tiuram, metano, o carba mix, como diferentes alérgenos además del talco que en este caso funciona como irritante. En las personas que los usan la prueba de parche suele ser positiva. ${ }^{12}$

El 12.4\% empleó guantes en tres capas, lo que incrementaba la humedad y maceración, creando erosiones más fácilmente en la piel. Lo que demuestra que tres capas de guantes no aumentan la protección, pero sí el riesgo de dermatitis. $^{7}$

\section{Mascarillas o cubrebocas}

Para la salvaguarda facial se usan diferentes tipos de máscaras, cubrebocas y lentes de protección que deben estar muy bien ajustados a la piel. Estos comprimen, aumentan la presión y disminuyen la irrigación sanguínea, causando hipoxia, isquemia y edema en partes blandas de la cara. La pérdida transepidérmica de agua por maceración y acúmulo de humedad en la superficie, reduce la capacidad del estrato córneo a resistir la presión y las fuerzas mecánicas, lo que conlleva indentaciones, eritema, ampollas, desepitelización y úlceras dolorosas que se podrían sobreinfectar (Figura 3). Las máscaras N95 suelen contener poliuretanos alergénicos. Las zonas más afectadas por los cubrebocas y

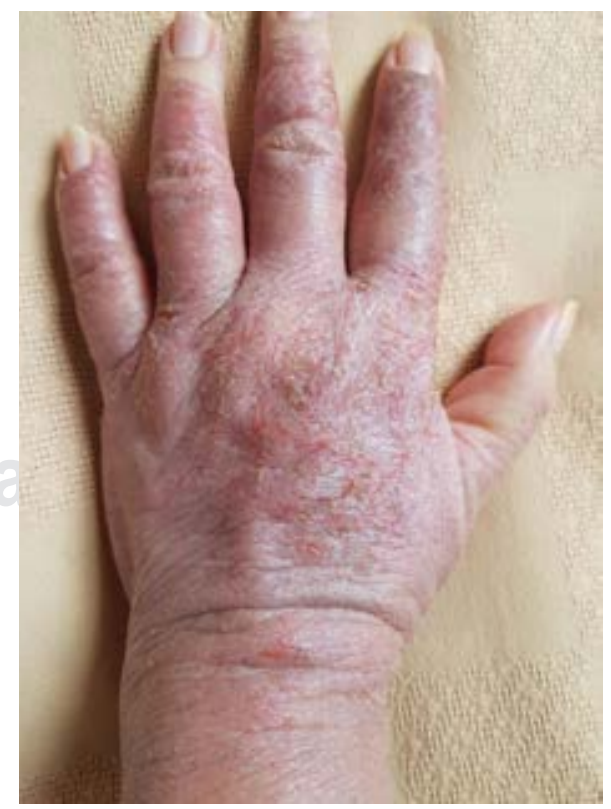

Figura 2:

Dermatitis de contacto. Dermatosis localizada a dorso de manos, bilateral y simétrico, caracterizado por placas con liquenificación, fisuras y eccema. 


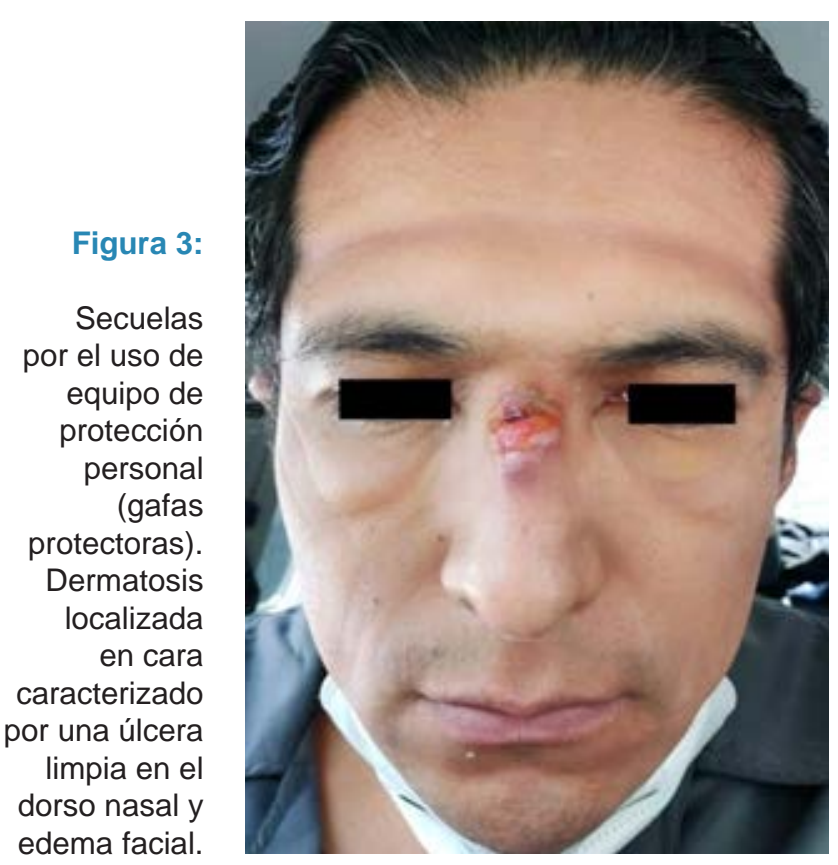

por los lentes de seguridad son el puente del dorso nasal hasta $83.1 \%$, el arco zigomático y el área de la frente. Otros elementos de riesgo presentes y a considerar importantes son el antecedente de dermatitis atópica y el invierno. ${ }^{12}$

Secundaria al uso de las mascarillas N95 se observó una prevalencia del $51.4 \%$ de prurito facial y $35.8 \%$ de rash facial. ${ }^{7}$ En la población general, el uso de cubrebocas KN95 o incluso de tela crea una zona en donde se acumula el calor, la humedad y la fricción lo que ocluye los folículos pilosos y favorece el maskné, término empleado para este acné desarrollado en un paciente que previamente no lo tenía (Figura 4). La piel detrás de las orejas también puede sufrir daño por presión y fricción del cordón elástico del cubrebocas.

Erickson y sus colegas, en el Centro Médico de la Universidad de Duke, proponen el uso de un casco modificado de Stryker Flyte ${ }^{\odot}$ que cubre totalmente la cara y el cuello, para evitar los problemas con los lentes de protección y careta que enfrenta el cirujano al usar lupas y luces. ${ }^{13}$

\section{Traje de equipo de protección personal (EPP)}

El traje, parte del EPP, al estar sellado, hermético y de plástico, genera calor y favorece reacciones de miliaria. Es más frecuente ver la urticaria de contacto por los adhesivos y plásticos. $^{10}$

Otras enfermedades asociadas al EPP son infecciones micóticas superficiales secundarias, por ejemplo tinea corporis, tinea pedis o tinea manum de las variedades interdigital o vesiculosa. Enfermedades como dishidrosis o ponfólix, y la foliculitis en cuero cabelludo, pueden verse agravados por la prolongada oclusión. ${ }^{14,15}$

\section{DERMATITIS DE CONTACTO}

Para prevenir la transmisión del virus se han adoptado muchas medidas; de las más importantes son lavarse las manos con frecuencia y descontaminar las superficies con desinfectantes específicos registrados por la agencia de protección ambiental (EPA).

EI CDC describe esta higiene manual adecuada con el lavado con jabón y agua tibia o fría durante 20 segundos, o el uso de desinfectantes a base de alcohol con al menos un $60 \%$ de alcohol. Los desinfectantes que cumplen con los criterios de la EPA para su uso contra el SARS-CoV-2 contienen ingredientes activos, por ejemplo amonio cuaternario, hipoclorito de sodio, ácido peroxiacético, peróxido de hidrógeno y alcoholes, muchos de los cuales son irritantes o alérgenos cutáneos conocidos.

Las consecuencias de la frecuente higiene de manos incluyen sequedad de la piel, la dermatitis de contacto irritante y la de contacto alérgica. La sequedad de dicha superficie es un signo temprano de daño a la barrera cutánea natural, que puede resultar del uso recurrente de detergentes emulsionantes, que agotan los lípidos en el estrato córneo. Entre los lípidos y las sustancias solubles en agua que se eliminan se encuentran los antibacterianos naturales, su pérdida conduce a un mayor crecimiento de

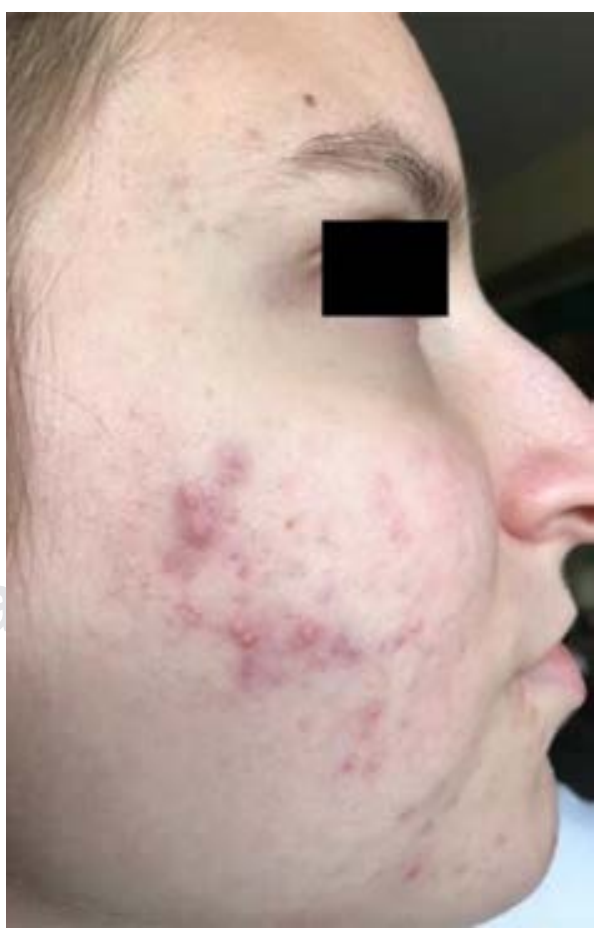

Figura 4:

Maskné. Dermatosis localizada en cara caracterizado por comedones y pápulas de reciente inicio en relación con el uso de cubrebocas. 
microorganismos transitorios y patógenos. Los desinfectantes a base alcohol disuelven los lípidos de las palmas, lo que también es capaz de contribuir a la disfunción de la barrera. ${ }^{16}$

Una práctica común en la población, que es ajena al personal de salud, es el uso de guantes de látex o nitrilo para sus actividades diarias, esto genera una combinación de factores dañinos: la eliminación de lípidos de barrera por limpieza con detergente y antisepsia con alcohol seguida de una pérdida de humectantes y agua del estrato córneo y la sobrehidratación de dicho estrato por el sudor atrapado dentro de los guantes. Juntos facilitan la invasión de irritantes y alérgenos que provocan respuestas inflamatorias en la dermis, generando dermatitis de contacto. ${ }^{17}$ Los síntomas de esta dolencia incluyen sequedad, aspereza, picazón, ardor, eritema, edema, ampollas, descamación y fisuras. ${ }^{16}$

Una forma menos común de dermatitis de contacto es la alérgica, que puede ocurrir cuando los pacientes tienen reacciones de hipersensibilidad a fragancias, conservantes o antimicrobianos químicos en detergentes o desinfectantes. Entre los desinfectantes registrados por la EPA para el SARS-CoV-2, el ingrediente activo más común es el amonio cuaternario.

Se ha observado un incremento en la incidencia de dermatitis de contacto e irritativa de contacto, ya que la frecuencia de limpieza de manos, al igual que la desinfección de superficies se ha incrementado por la necesidad de evitar la propagación de virus. Igualmente se han estandarizado prácticas inadecuadas al realizar mezclas de distintos detergentes o desinfectantes, buscando la eliminación por completo de patógenos y bacterias de superficies inertes, que en consecuencia deterioraran la barrera cutánea.

\section{ACNÉ, ROSÁCEA Y DERMATITIS SEBORREICA}

En un estudio en China, se observó que el 49\% de los sujetos reportaron reacciones cutáneas en la cara, relacionadas con el uso de la máscara: prurito en el $14.9 \%$ de ellos, eritema en $12.6 \%$ y sequedad en $11.6 \%$, que fueron las manifestaciones más frecuentes. Además, el $43.6 \%$ de los aquejados con acné, el $100 \%$ de los que padecen rosácea y el $37.5 \%$ de aquellos con dermatitis seborreica presentaron exacerbación de sus dermatosis. ${ }^{18}$

Otro estudio polaco demostró que el picor asociado con el uso de mascarillas estaba presente en el $19.6 \%$ de los sujetos. En particular, los sujetos con dermatitis atópica, seborreica y acné tenían un riesgo significativamente mayor de desarrollar picazón. ${ }^{19}$

En México, en la consulta privada, durante los meses de pandemia de fines de marzo a principios de octubre del 2020, se han observado la aparición inicial o recidivas o exacerbación de varias dermatosis en los pacientes, por ejemplo el acné, la rosácea, la dermatitis seborreica, la perioral, la demodecidosis y otras que tienen relación con factores predisponentes como el estrés, los cambios en los hábitos higiénicos, dietéticos, el uso de cubrebocas, el no beber agua, el tabaquismo, abuso de medicamentos y otras drogas, con realizar ejercicio y con trastornos del sueño, entre otros.

Los afectados referían varios elementos predisponentes, entre ellos: ansiedad, cambios en su dieta, estar comiendo con horarios irregulares y alimentos y/o bebidas que predisponen, provocan recidiva o empeoramiento, sean lácteos, alimentos de alta carga glucémica (dulces, postres, Nutella, etc.), cereales y barritas, galletas, o tentempiés como cacahuates, almendras, nueces, otras comidas chatarra, el saltar horarios de comida, abuso de refrescos y bebidas alcohólicas, principalmente en los pacientes de sexo masculino. También muchos de ellos referían no bañarse diario, ni tener medidas higiénicas de lavarse la cara dos veces al día.

Del mismo modo se anotó el uso de mascarillas de diferentes materiales, algunos alergénicos, en interacción con sus secreciones nasales y salivales por muchas horas, en donde se hace un microambiente de humedad, aumenta la temperatura local y hay disminución de oxígeno, con modificación de la barrera cutánea y su microbiota, causando varias disbiosis como rosácea, dermatitis seborreica, perioral, demodecidosis y otras. ${ }^{14,20,21}$

\section{Acné}

Los pacientes acuden a consulta por brotes iniciales de acné o agravamiento de éste. El acné también se ve favorecido por el abandono de su tratamiento anterior, o el desabasto de productos a causa de la pandemia, la falta de higiene, el tipo de mascarilla utilizado, la automedicación con multivitamínicos, omegas combinados con complejo B y proteínas que ellos toman para supuestamente aumentar las defensas, la exposición a la radiación solar o a la luz visible sin fotoprotección y por pasar horas con los dispositivos electrónicos aun quedándose en casa.

La exposición a la radiación ultravioleta (RUV) y a la luz visible producen inflamación de las lesiones y oxidación del sebo, generando peróxido de escualeno comedogénico, que aunado al sudor y humedad de los que usan cubrebocas, empeora el cuadro. La hiperpigmentación postinflamatoria (DPI) ocurre con más frecuencia en las mujeres, estudios comparativos refieren un $27.4 \%$ del sexo femenino a comparación de un $11.7 \%$ en el sexo masculino, también en las féminas hay una mayor frecuencia de acné excoriado, lo cual se exacerba con el estrés. ${ }^{22,23}$

Ese sentimiento de tensión física o emocional es un factor causante y que puede exacerbar el acné. Existe una 
correlación entre el estrés y la severidad del acné. Se ha confirmado que así se aumentan las concentraciones de glucocorticoides y andrógenos. Se desconoce si estos incrementos son relevantes en las erupciones de acné, lo más probable es que representen sólo una parte de un sistema multifactorial mucho más complejo de la fisiopatología. El acné aumenta el estrés que hoy día afecta a una sociedad exigente, causando problemas en el trabajo, familiares y sociales. ${ }^{24}$ El mismo trastorno aumenta los neuropéptidos, como la sustancia P (de la inflamación). Hay mediadores químicos liberados por queratinocitos epidérmicos, la piel con acné aumenta la expresión de genes relacionados con la hormona liberadora de corticotropina $(\mathrm{CRH})$ que regula la síntesis de lípidos en los sebocitos. La alteración y reducción en el tiempo de sueño (insomnio o apnea) y el estrés afectan las funciones cardiovascular, sexual, cognitiva, al sistema inmune (aumentando los linfocitos T/CD4, y la IL-17), altera la secreción hormonal y el metabolismo, lo cual ha sido más marcado en esta pandemia. ${ }^{22}$

La microbiota cutánea varía según la topografía, la edad, el género, los cambios hormonales y los componentes ambientales (el uso de jabón, cosmético, antibiótico, ocupación, temperatura, humedad y exposición a RUV).

La conexión entre el acné y la disfunción gastrointestinal puede originarse en el cerebro. Apoyar esta hipótesis explica el agravamiento del acné inducido por el estrés. Estudios experimentales en animales y humanos han demostrado que el trastorno afecta a la microflora intestinal normal (especies Lactobacillus y Bifidobacterium). Los estresores sicológicos hacen que los microbios intestinales produzcan neurotransmisores (acetilcolina, serotonina, noradrenalina) que cruzan la mucosa intestinal para entrar en el torrente sanguíneo, provocando inflamación sistémica. El papel del estrés (depresión y ansiedad) en el agravamiento del acné se debe a su repercusión en la digestión. Este malestar altera la pared intestinal debido al sobrecrecimiento bacteriano, al trastorno del tránsito y a la alteración de la función de barrera intestinal con modificación de la microbiota intestinal. El estreñimiento se vincula con aumento de la permeabilidad intestinal y causa disminución de la concentración de bacterias saludables, como lactobacilos y bifidobacterias, contribuyendo a la inflamación de la piel. ${ }^{25-27}$

El acné también se ha reportado dentro del grupo de las dermatosis relacionadas con el equipo de protección personal y las medidas de higiene asociadas a la pandemia por COVID-19 (en cara, del 12 al 87\%). El uso prolongado de mascarilla y lentes de seguridad agrava el acné, mecanismos posibles incluyen la ruptura de comedones inducida por presión y fricción, oclusión del conducto pilosebáceo, disfunción de la microcirculación debido a la presión a largo plazo y un ambiente húmedo propicio para la proliferación de bacterias. ${ }^{18,19}$

\section{Rosácea}

Se conoce que, en la patogenia de la rosácea, contribuyen principios como la inmunidad y vascularidad anormales, una desregulación neurogénica, disfunción de la barrera cutánea, presencia de microorganismos cutáneos, como el microácaro Demodex folliculorum, y daño por la radiación ultravioleta (RUV). ${ }^{28}$

Son factores desencadenantes, entre otros, el calor, estrés, comidas condimentadas, bebidas calientes, tabaquismo, alcohol, RUV y luz visible, se han visto exacerbados durante esta pandemia.

Además, la rosácea se asocia con una barrera cutánea deteriorada, que provoca un exceso de pérdida transepidérmica de agua (PTEA) con una piel seca, propensa a descamación y sensible con sensación urente y de prurito. ${ }^{28}$

Múltiples ingredientes influyen en la colonización microbiana, incluida la aerobicidad, la humedad, la temperatura, el pH, la composición de lípidos, la edad y el sexo. Los factores endógenos como el sudor, el sebo y la producción de hormonas pueden diferir mucho entre individuos, al igual que las influencias exógenas, siendo los principales el clima, la dieta, los artículos de tocador y los medicamentos. ${ }^{29}$

La microflora residente de las áreas húmedas ocluidas, por ejemplo, varía mucho de la de las áreas expuestas con alta densidad de glándulas sebáceas. Por este motivo, los pacientes con rosácea han presentado recidiva o empeoramiento de su dermatosis, relacionado al uso de cubrebocas.

Por otro lado, se tienen las vitaminas del complejo B como la B2 (riboflavina), la B6 (piridoxina) y la B12 (cianocobalamina), que podrían provocar un empeoramiento del acné vulgar o la erupción de un exantema acneiforme. Es mucho más frecuente que se afecten mujeres que hombres.

Clínicamente, suelen aparecer pápulas y pústulas diseminadas por la cara, sobre todo en la frente y en las mejillas (Figura 5). También se han descrito casos de rosácea fulminante tras la administración de dichas vitaminas, que se produjeron de forma dosis-dependiente en la mayoría de los casos.

La rosácea inducida por vitamina B no suele responder de forma adecuada a las pautas terapéuticas habituales, pero mejora rápidamente al suspender el suplemento vitamínico. A modo de conclusión, la administración de derivados de la vitamina $B$ debe considerarse entre las causas farmacológicas de inicio o empeoramiento de la rosácea. En esta pandemia muchos pacientes se han automedicado con complejo B por lo que ha sido un factor predisponente. ${ }^{30,31}$

El rol del estrés en la rosácea es a través de una acción sobre la digestión, semejante al acné, lo cual ya fue mencionado. ${ }^{31}$ 


\section{Dermatitis seborreica}

La forma seborreica es una dermatosis eritematoescamosa, inflamatoria, de etiología multifactorial y de evolución crónica. Se presenta en todos los grupos etarios y se encuentra asociada con pacientes con síndrome de inmunodeficiencia adquirida o trastornos neurológicos, como la enfermedad de Parkinson. Afecta del 1 al 3\% de la población en general, del 3 al 5\% de los adultos jóvenes y del 20 al 83\% de los afectados con síndrome de inmunodeficiencia adquirida. ${ }^{32,33}$

En el adulto afecta la cara en un $87 \%$, el cuero cabelludo en $70.3 \%$, el tórax anterior en $26.8 \%$, los miembros inferiores en $2.3 \%$, los miembros superiores en $1.3 \%$ y otros sitios en $5.4 \% .^{33}$

Existen varios factores etiopatogénicos, dentro de los biológicos está la colonización por hongos, específicamente se menciona el papel de las levaduras del género Malassezia spp. en la patogenia, aun siendo un constituyente de la microbiota. La presencia de $M$. globosa y $M$. restricta se correlaciona con la apariencia y severidad de las lesiones. Los metabolitos de estas levaduras ocasionan diferenciación aberrante de queratinocitos, dando un estrato córneo anormal, ocasionando una disrupción en la función de la barrera epidérmica. ${ }^{34,35}$

Dentro de los componentes hormonales está el papel de los andrógenos, al ser más frecuente en hombres. Su desarrollo en la pubertad y mayor actividad hormonal entre los 30 y 60 años. ${ }^{36}$

Los episodios agudos de esa perturbación se exacerban por el rol de los factores emocionales y de estrés, como la ansiedad y la depresión, tal cual ha sucedido en esta etapa de la pandemia por COVID-19.

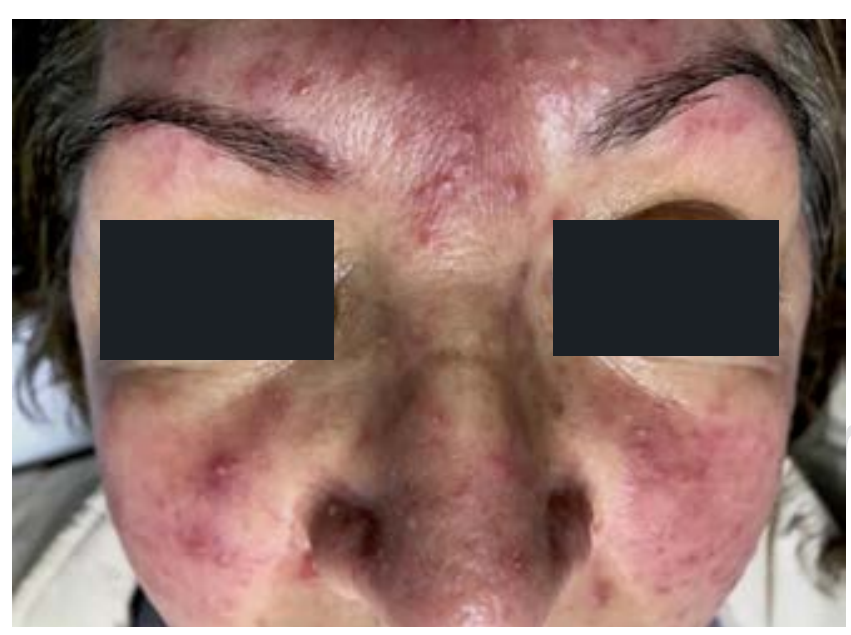

Figura 5: Rosácea. Dermatosis localizada en cara de predominio en frente y mejillas caracterizado por pápulas y pústulas. Cuadro exacerbado en la pandemia.
Los elementos ambientales influyen, entre ellos el invierno, la temperatura baja, pues empeora los cuadros en pacientes que viven en zonas de altitud, ya que tienen mayor exposición a luz ultravioleta o a la luz visible, como ha sucedido durante esta catástrofe, con el exceso de horas frente a los dispositivos. ${ }^{37,38}$ También el uso de mascarillas (cubrebocas, barbijo) por COVID-19 la agravan. ${ }^{18}$

Los reportes refieren que $37.5 \%$ de los pacientes con dermatitis seborreica presentaron empeoramiento de sus dermatosis. ${ }^{18,20}$

\section{ALOPECIA}

El efluvio telógeno se ha presentado tanto en enfermos con COVID-19 como en personas aparentemente sanas, asociado al estrés de la pérdida de un familiar, del trabajo, problemas financieros o por el confinamiento per se. De acuerdo a un grupo español, en los contagiados con esta enfermedad, la alopecia se hace evidente a semanas de iniciarse la misma, relacionado a la fiebre como factor desencadenante.

Se ha observado que la alopecia androgenética es más prevalente en pacientes con infección grave y neumonía. Se ha propuesto a esta forma de alopecia como un factor predictivo de severidad.

Otras alteraciones del pelo que han aumentado con la pandemia son la alopecia areata y la dermatitis seborreica.

\section{HERPES ZÓSTER}

El herpes zóster es la reactivación del virus de varicela zóster que queda latente en los ganglios de las raíces dorsales o de los pares craneales, posterior a una primoinfección. Se manifiesta por una dermatosis constituida por vesículas, que sigue el trayecto de un dermatoma y se acompaña de dolor neuropático (Figura 6). La edad es el factor de riesgo más importante, ya que el envejecimiento disminuye la inmunidad celular, lo que lleva a una reducción en la protección ante el virus de varicela zóster. ${ }^{39,40}$ Otros factores de riesgo descritos son un estado de inmunosupresión como el $\mathrm{VIH}$, el género femenino, antecedentes heredofamiliares, enfermedades autoinmunes, por ejemplo artritis reumatoide, trauma, radiación; además de algunos medicamentos y situaciones no confirmadas, como el estrés. ${ }^{39,41-43}$

En el transcurso de la pandemia de coronavirus se han reportado casos de la asociación de este herpes con el SARS-CoV-2 ${ }^{41,44,45}$ y un aumento de los mismos comparado con años previos, en pacientes en los que la única manifestación es el herpes zóster, por lo que no se les realiza la prueba RT-PCR para coronavirus o bien esta prueba resulta negativa. ${ }^{46}$ En la práctica privada de una de las autoras se ha visto un incremento de casos de esta 


\section{Figura 6:}

$$
\begin{array}{r}
\text { Herpes zóster. } \\
\text { Dermatosis } \\
\text { localizada } \\
\text { en rama } \\
\text { mandibular } \\
\text { del trigémino, } \\
\text { caracterizado } \\
\text { por vesículas } \\
\text { acompañada } \\
\text { de dolor } \\
\text { neuropático. }
\end{array}
$$

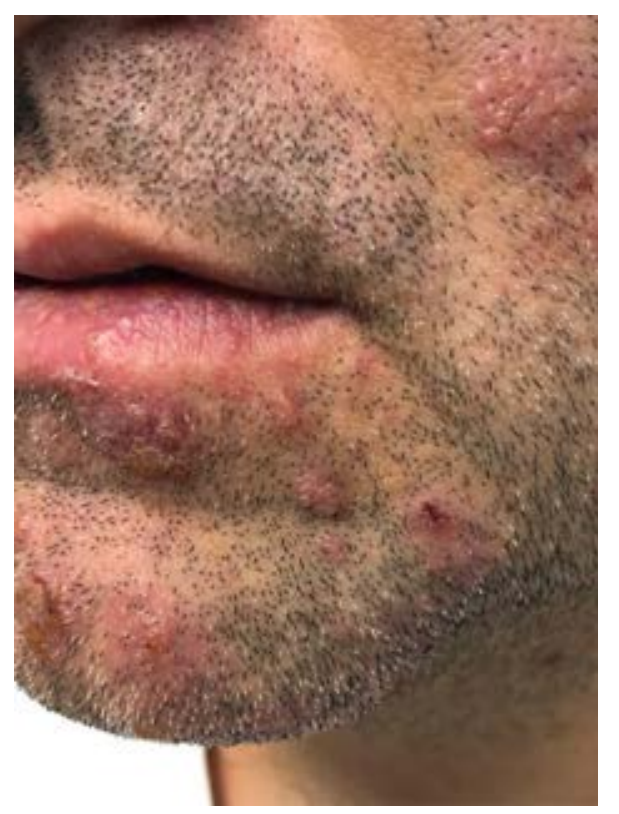

variedad de herpes, en los siete meses de emergencia, de 0.1 a 1.3 por 100 enfermos evaluados en el mismo periodo.

En el hospital, en el transcurso de la plaga, en el grupo de dermatólogos se han visto 27 casos de herpes zóster, con predominio en mujeres con una relación de 2:1, edad media de 62 años con un rango de 21 a 91 años. La topografía más frecuente es la torácica, seguida del trigémino. A ningún caso se le realizó RT-PCR para SARS-CoV-2, al no presentar sintomatología adicional a la de dicho herpes.

Los casos mencionados no difieren de los habituales en género, edad y topografía. La incidencia de herpes zóster ha aumentado cuatro veces en las últimas seis décadas y no se le ha podido atribuir a un aumento de la edad en la población. ${ }^{47,48}$

En los casos de herpes zóster y COVID-19, la reactivación se debe a que el germen provoca una disminución funcional y numérica de linfocitos T CD4 y CD8, al igual que las células NK (natural killers) creando un estado de inmunosupresión. ${ }^{44,49}$ En el caso de los PCR negativos este aumento pudiera estar asociado con el estrés tan importante que se padece por todas las condiciones de la pandemia.

Este tipo de herpes podría ser una manifestación de SARS-CoV-2, por lo que se sugiere realizar la prueba diagnóstica y manejarlos como potencialmente infectocontagiosos. ${ }^{44}$

\section{DISCUSIÓN}

En tiempos de pandemia, ante una nueva enfermedad, un nuevo estilo de vida en un ambiente cambiante, se ven los estragos no únicamente del virus sino de los intentos por evitar los contagios, el impacto sicológico y el económico. La piel es un espejo de todas estas circunstancias.

La importancia de conocer y reconocer una farmacodermia en los pacientes con COVID-19 es no confundirla con una manifestación del patógeno y que aumente la morbimortalidad de por sí alta.

Con el objetivo de prevenir contagios del SARS-CoV-2, se está causando daño cutáneo con los EPP. Es aquí donde juega un papel importante nuevamente la prevención de tales eventos. Se propone que la piel de la cara deberá limpiarse con jabones sin detergente e hidratarse con emolientes y lubricantes de cremas o geles no comedogénicos, al menos una hora antes de usar el EPP para así reducir la fricción. No se recomiendan emolientes a base de petrolatos por su efecto oclusivo y comedogénico. Se pueden prevenir las erosiones con la aplicación de apósitos hidrocoloides debajo de los sitios de presión. Las cintas o elásticos no deberán de ser tan apretados. En caso de urticaria por presión los antihistamínicos tipo cetirizina o loratadina son los más recomendados. 7,10,11,50

Para prevenir el eccema de manos se recomienda no lavarlas con agua muy caliente, usar jabón suave sin detergente y secarlas muy bien, antes de aplicar emolientes. En caso de requerir el uso de desinfectantes es preferible que contengan etanol como componente principal. Si se requiere el uso prolongado de guantes, usar previamente humectantes hipoalergénicos e incluir el uso de guantes de algodón debajo de los guantes quirúrgicos, junto con talco, que disminuye la humedad.

El manejo del acné, rosácea, dermatitis de contacto o seborreica, o herpes zóster, no difieren del habitual. La importancia radica en su prevención, educación de la población y manejo oportuno.

Es probable que se siga aprendiendo de la catástrofe y el reto es mantenerse al día.

\section{REFERENCIAS}

1. Galván Casas C, Catalá A, Carretero Hernández G, Rodríguez-Jiménez P, Fernández-Nieto D, Rodríguez-Villa Lario A et al. Classification of the cutaneous manifestations of COVID-19: a rapid prospective nationwide consensus study in Spain with 375 cases. Br J Dermatol. 2020; 183 (1): 71-77. doi: 10.1111/bjd.19163.

2. Su CJ, Lee CH. Viral exanthem in COVID-19, a clinical enigma with biological significance. J Eur Acad Dermatol Venereol. 2020; 34 (6): e251-e252. doi: 10.1111/jdv.16469.

3. Freeman EE, McMahon DE, Lipoff JB, Rosenbach M, Kovarik C, Desai SR et al. The spectrum of COVID-19-associated dermatologic manifestations: An international registry of 716 patients from 31 countries. J Am Acad Dermatol. 2020; 83 (4): 1118-1129. doi: 10.1016/j.jaad.2020.06.1016.

4. Suchonwanit P, Leerunyakul K, Kositkuljorn C. Cutaneous manifestations in COVID-19: Lessons learned from current evidence. J Am Acad Dermatol. 2020; 83 (1): e57-e60. doi: 10.1016/j. jaad.2020.04.094. 
5. Litt JZ. Drug eruption reference manual. Including drug interactions. 10th edition. New York: CRP Press; 2004.

6. Honda H, Iwata K. Personal protective equipment and improving compliance among healthcare workers in high-risk settings. Curr Opin Infect Dis. 2016; 29 (4): 400-406. doi: 10.1097/ QCO.0000000000000280.

7. Yan Y, Chen H, Chen L, Cheng B, Diao P, Dong L et al. Consensus of Chinese experts on protection of skin and mucous membrane barrier for health-care workers fighting against coronavirus disease 2019. Dermatol Ther. 2020; 33 (4): e13310. doi: 10.1111/dth.13310.

8. Bhatia R, Sindhuja T, Bhatia S, Dev T, Gupta A, Bajpai M et al. latrogenic dermatitis in times of COVID-19: a pandemic within a pandemic. J Eur Acad Dermatol Venereol. 2020; 34 (10): e563-e566. doi: 10.1111/jdv.16710.

9. Guertler A, Moellhoff N, Schenck TL, Hagen CS, Kendziora B, Giunta RE et al. Onset of occupational hand eczema among healthcare workers during the SARS-CoV-2 pandemic: comparing a single surgical site with a COVID-19 intensive care unit. Contact Dermatitis. 2020; 83 (2): 108-114. doi: 10.1111/cod.13618.

10. Desai SR, Kovarik C, Brod B, James W, Fitzgerald ME, Preston A et al. COVID-19 and personal protective equipment: Treatment and prevention of skin conditions related to the occupational use of personal protective equipment. J Am Acad Dermatol. 2020; 83 (2): 675-677. doi: 10.1016/j.jaad.2020.05.032.

11. Hadjieconomou S, Hughes J, Kamath S. Occupational skin disease during the COVID-19 pandemic, as captured in a Dermatology staff clinic in the United Kingdom. J Eur Acad Dermatol Venereol. 2020; 34 (11): e670-e671. doi: 10.1111/jdv.16754.

12. Elston DM. Occupational skin disease among health care workers during the coronavirus (COVID-19) epidemic. J Am Acad Dermatol. 2020; 82 (5): 1085-1086. doi: 10.1016/j.jaad.2020.03.012.

13. Erickson MM, Richardson ES, Hernandez NM, Bobbert DW 2nd, Gall K, Fearis P. Helmet modification to PPE with 3D printing during the COVID-19 pandemic at duke university medical center: a novel technique. J Arthroplasty. 2020; 35 (7S): S23-S27. doi: 10.1016/j. arth.2020.04.035.

14. Long H, Zhao H, Chen A, Yao Z, Cheng B, Lu Q. Protecting medical staff from skin injury/disease caused by personal protective equipment during epidemic period of COVID-19: experience from China.J Jur Acad Dermatol Venereol. 2020; 34 (5): 919-921. doi: 10.1111/jdv.16388.

15. Zhou NY, Yang L, Dong LY, Li Y, An XJ, Yang J et al. Prevention and treatment of skin damage caused by personal protective equipment: experience of the first-line clinicians treating 2019-nCoV infection. International Journal of Dermatology and Venereology. 2020: 10.1097/ JD9.0000000000000085. doi: 10.1097/JD9.0000000000000085. [Published on line]

16. Kownatzki E. Hand hygiene and skin health. J Hosp Infect. 2003; 55 (4): 239-245. doi: 10.1016/j.jhin.2003.08.018.

17. Larson E, Friedman C, Cohran J, Treston-Aurand J, Green S. Prevalence and correlates of skin damage on the hands of nurses. Heart Lung. 1997; 26 (5): 404-412. doi: 10.1016/s0147-9563(97)90027-3.

18. Veraldi S, Angileri L, Barbareschi M. Seborrheic dermatitis and antiCOVID-19 masks. J Cosmet Dermatol. 2020; 19 (10): 2464-2465. doi: 10.1111/jocd.13669.

19. Han C, Shi J, Chen Y, Zhang Z. Increased flare of acne caused by long-time mask wearing during COVID-19 pandemic among general population. Dermatol Ther. 2020; 33 (4): e13704. doi: 10.1111/ dth.13704.

20. Giacalone S, Minuti A, Spigariolo CB, Passoni E, Nazzaro G. Facial dermatoses in the general population due to wearing of personal protective masks during the COVID-19 pandemic: first observations after lockdown. Clin Exp Dermatol. 2021; 46 (2): 368-369. doi: 10.1111/ced.14376.

21. Zuo Y, Hua W, Luo Y, Li L. Skin reactions of N95 masks and medial masks among health-care personnel: A self-report questionnaire survey in China. Contact Dermatitis. 2020; 83 (2): 145-147. doi: 10.1111/cod.13555.

22. Albuquerque RG, Rocha MA, Bagatin E, Tufik S, Andersen ML. Could adult female acne be associated with modern life? Arch Dermatol Res. 2014; 306 (8): 683-688. doi: 10.1007/s00403-014-1482-6.

23. Dréno B, Layton A, Zouboulis CC, López-Estebaranz JL, ZalewskaJanowska A, Bagatin E et al. Adult female acne: a new paradigm. J Eur Acad Dermatol Venereol. 2013; 27 (9): 1063-1070. doi: 10.1111/ jdv.12061.

24. Saldaña M, Fierro-Arias L. Acné y depresión. Dermatol Rev Mex. 2019; 63 (Suppl: 1): 18-24.

25. Bowe WP. Could probiotics be the next big thing in acne and rosacea treatments, Schaumburg, IL: Interview with the American Academy of Dermatology: 2014. Retrieved from: https://www.aad.org/storiesand-news/news-releases/could-probiotics-be-the-next-big-thing-inacne-and-rosacea-treatments

26. Bowe WP. Probiotics in acne and rosacea. Cutis. 2013; 92 (1): 6-7.

27. Baquerizo Nole KL, Yim E, Keri JE. Probiotics and prebiotics in dermatology. J Am Acad Dermatol. 2014; 71 (4): 814-821. doi: 10.1016/j.jaad.2014.04.050.

28. Cardwell LA, Alinia H, Moradi Tuchayi S, Feldman SR. New developments in the treatment of rosacea - role of once-daily ivermectin cream. Clin Cosmet Investig Dermatol. 2016; 9: 71-77. doi: 10.2147/CCID.S98091.

29. Holmes AD. Potential role of microorganisms in the pathogenesis of rosacea. J Am Acad Dermatol. 2013; 69 (6): 1025-1032. doi: 10.1016/j.jaad.2013.08.006.

30. Martín JM, Pellicer Z, Bella R, Jordá E. Rosácea desencadenada por un complejo vitamínico del grupo B. Actas Dermosifiliogr. 2011; 102 (3): 223-224. doi: 10.1016/j.ad.2010.06.028.

31. Arias MI. Rosácea y dieta. En: Kaminsky A, Piquero JM, Herane MI, Diez de Medina JC, Flórez-White M. Rosácea, una visión integral. Buenos Aires: GILER; 2018. Cap. 33: pp. 374-377.

32. Sampaio AL, Mameri AC, Vargas TJ, Ramos-e-Silva M, Nunes AP, Carneiro SC. Seborrheic dermatitis. An Bras Dermatol. 2011; 86 (6): 1061-1071; quiz 1072-1074. doi: 10.1590/s036505962011000600002.

33. Clark GW, Pope SM, Jaboori KA. Diagnosis and treatment of seborrheic dermatitis. Am Fam Physician. 2015; 91 (3): 185-190.

34. Del Rosso JQ. Adult seborrheic dermatitis: a status report on practical topical management. J Clin Aesthet Dermatol. 2011; 4 (5): $32-38$

35. Dessinioti C, Katsambas A. Seborrheic dermatitis: etiology, risk factors, and treatments: facts and controversies. Clin Dermatol. 2013; 31 (4): 343-351. doi: 10.1016/j.clindermatol.2013.01.001.

36. Borda LJ, Wikramanayake TC. Seborrheic dermatitis and dandruff: a comprehensive review. J Clin Investig Dermatol. 2015; 3 (2): 10.13188/2373-1044.1000019. doi: 10.13188/23731044.1000019.

37. Medina Castillo DE. Dermatitis seborreica: una revisión. DCMQ. 2014; 12 (2): 135-140.

38. Reider N, Fritsch PO. Otras erupciones eccematosas. En: Bolognia JL, editor. Dermatología. 4⿳a ed. España: Elsevier; 2018. Cap. 13: pp. 228-232.

. Yawn BP, Gilden D. The global epidemiology of herpes zoster. Neurology. 2013; 81 (10): 928-930.

40. Cohen JI. Clinical practice: herpes zoster. N Engl J Med. 2013; 369 (3): 255-263. doi: 10.1056/NEJMcp1302674.

41. Saati A, Al-Husayni F, Malibari AA, Bogari AA, Alharbi M. Herpes zoster co-infection in an immunocompetent patient with COVID-19. Cureus. 2020; 12 (7): e8998. doi: 10.7759/cureus.8998.

42. Wung PK, Holbrook JT, Hoffman GS, Tibbs AK, Specks U, Min YI et al. Herpes zoster in immunocompromised patients: incidence, timing, and risk factors. Am J Med. 2005; 118 (12): 1416. doi: 10.1016/j. amjmed.2005.06.012. 
43. Kawai K, Yawn BP. Risk factors for herpes zoster: a systematic review and meta-analysis. Mayo Clin Proc. 2017; 92 (12): 1806-1821. doi: 10.1016/j.mayocp.2017.10.009.

44. Elsaie ML, Youssef EA, Nada HA. Herpes zoster might be an indicator for latent COVID 19 infection. Dermatol Ther. 2020; 33 (4): e13666. doi: $10.1111 /$ dth.13666.

45. Shors AR. Herpes zoster and severe acute herpetic neuralgia as a complication of COVID-19 infection. JAAD Case Rep. 2020; 6 (7): 656-657. doi: 10.1016/j.jdcr.2020.05.012.

46. Ferreira ACAF, Romão TT, Macedo YS, Pupe C, Nascimento OJM; Fellow of the American Academy of Neurology (FAAN). COVID-19 and herpes zoster co-infection presenting with trigeminal neuropathy. Eur J Neurol. 2020; 27 (9): 1748-1750. doi: 10.1111/ene.14361.

47. Schmader K. Herpes zoster. Ann Intern Med. 2018; 169 (3): ITC19ITC31. doi: 10.7326/AITC201808070.
48. Zheng M, Gao Y, Wang G, Song G, Liu S, Sun D et al. Functional exhaustion of antiviral lymphocytes in COVID-19 patients. Cell Mol Immunol. 2020; 17 (5): 533-535. doi: 10.1038/s41423-020-0402-2.

49. Xu R, Zhou Y, Cai L, Wang L, Han J, Yang X et al. Co-reactivation of the human herpesvirus alpha subfamily (herpes simplex virus-1 and varicella zoster virus) in a critically ill patient with COVID-19. Br J Dermatol. 2020; 183 (6): 1145-1147. doi: 10.1111/bjd.19484.

50. Lan J, Song Z, Miao X, Li H, Li Y, Dong L et al. Skin damage among health care workers managing coronavirus disease-2019. J Am Acad Dermatol. 2020; 82 (5): 1215-1216. doi: 10.1016/j. jaad.2020.03.014.

Conflicto de intereses: Sin conflicto de intereses. 